\title{
Coulisses
}

Revue de théâtre

10 | Printemps 1994

Varia

\section{Une nouvelle scène en région... Le théâtre du Lavoir à Pontarlier}

Pierre Louis

\section{(2) OpenEdition}

12 Journals

Édition électronique

URL : http://journals.openedition.org/coulisses/2835

DOI : $10.4000 /$ coulisses.2835

ISSN : 2546-9460

Éditeur

Presses universitaires de Franche-Comté

\section{Édition imprimée}

Date de publication : 1 juin 1994

Pagination : 19

ISSN : 1150-594X

\section{Référence électronique}

Pierre Louis, « Une nouvelle scène en région... Le théâtre du Lavoir à Pontarlier », Coulisses [En ligne], 10 | Printemps 1994, mis en ligne le 15 mars 2019, consulté le 22 octobre 2019. URL : http:// journals.openedition.org/coulisses/2835; DOI : 10.4000/coulisses.2835

Ce document a été généré automatiquement le 22 octobre 2019

Coulisses 


\title{
Une nouvelle scène en région... Le théâtre du Lavoir à Pontarlier
}

\author{
Pierre Louis
}

1 Engagée par la ville de Pontarlier avec l'aide du Centre d'animation du Haut-Doubs, de la DRAC de Franche-Comté, du Conseil Régional, la rénovation du Théâtre du Lavoir vient de doter le Haut-Doubs et sa capitale d'un nouvel espace de création et de rencontre autour des arts du spectacle, un espace où l'on a su préserver le cachet ancien tout en mettant aux normes les installations techniques et en offrant enfin le confort aux spectateurs et aux artistes.

2 La participation de l'Etat et de la Région à cette rénovation, comme les missions confiées au C.A.H.D. par la Ville et par le Département, sous-entendaient l'existence sur ce lieu d'un projet culturel. Le théâtre du Lavoir se présente donc comme une salle municipale de 140 places, attribuée au C.A.H.D. en vertu d'une convention particulière, que la ville peut mettre à disposition d'autres utilisateurs, mais en sachant que programmation et utilisation répondent à un souci de cohérence et d'exigence artistique. Souci également de complémentarité : deux autres "scènes ", le Théâtre Municipal et le Château de Joux, dont l'équipement vient d'être amélioré, permettront tout au long d'une saison de mieux répartir les spectacles en fonction de leur caractère et de leurs dimensions.

3 Lieu de création théâtrale, de diffusion, d'échanges et de tentatives au cœur d'une cité et d'une région qui, par vocation, cultivent l'autonomie locale mais savent plus souvent qu'on ne le croit s'ouvrir au vent du large et au voisinage, le Théâtre du lavoir permettra au C.A.H.D. et aux Comédiens des Nuits de Joux de travailler avec d'autres équipes, d'accueillir des propositions de spectacles provenant non seulement de la création professionnelle mais aussi du milieu scolaire et associatif, dans l'intention partagée de nourrir un acte artistique fécond et fraternel.

4 Inscrire un théâtre sur la carte d'une ville, ouvrir une nouvelle scène dans une région comme la nôtre est un acte politique qui honore ceux qui l'ont voulu, mais qui les engage encore plus pour l'avenir. Car ce lieu qu'on fait renaître, peut se trouver dépossédé de son avenir si la volonté politique ne cherche pas à lui donner les moyens 
de fonctionner correctement. C'est l'engagement de la cité dans toutes ses composantes, à commencer bien sûr, par le public, qui donnera ici la mesure ou la brisure des rêves qui nous animent, dans le dur désir de durer, cernant et discernant inlassablement les réalités du monde d'aujourd'hui et dans ces réalités, les possibilités d'éclosion des pratiques artistiques, ici et maintenant.

5 Théâtre sur plateau nu posé au sol, théâtre ruche, théâtre coffre magique, avec ses caches et ses recoins, cintres entrecroisés de la charpente comme une arche renversée il nous reste à faire habiter ce lieu accueillant, de nos songes enfouis et révélés, de notre possible de gloire...

\section{AUTEUR}

\section{PIERRE LOUIS}

Directeur du C.A.H.D. (Centre d'Animation du Haut-Doubs) 